\title{
Benchmarking leakage from water reticulation systems in South Africa
}

\author{
Caryn Seago ${ }^{1 *}$, Jay Bhagwan ${ }^{2}$ and Ronnie McKenzie ${ }^{1}$ \\ ${ }^{1}$ WRP Consulting Engineers; PO Box 1522, Brooklyn Square, Pretoria 0075, South Africa \\ ${ }^{2}$ Water Research Commission, PO Box 824, Pretoria 0001, South Africa
}

\begin{abstract}
A project to assess the levels of leakage in 30 water utilities throughout South Africa was initiated by the Water Research Commission. The BENCHLEAK software was used to evaluate the water utilities and performance indicators calculated by the model were used to compare levels of non-revenue water. Results showed that utilities ranked differently according to the different indicators, and that the South African results are similar to world norms.

Feed back from the water utilities showed that some of the data requested were confusing and required clarity. The number of service connections, apparent losses and length of pipe between the street edge and the meter were looked at in more detail. Standard drawings were developed to assist water utilities in determining their number of service connections. A table is presented to assess the apparent losses of each water utility in a more pragmatic way.
\end{abstract}

\section{Introduction}

There is an increasing awareness in South Africa that water is limited and that careful management should be applied when dealing with this scarce resource. Water lost from potable water distribution systems remains a major issue when examining the overall water wasted throughout the country. The BENCHLEAK software was developed through the Water Research Commission to provide a simple yet pragmatic approach to the evaluation of leakage from potable water distribution systems. The model is used to assist water utilities to evaluate the levels of leakage and nonrevenue water in their water distribution systems.

A project was previously initiated by the Water Research Commission in order to develop a standardised software package (BENCHLEAK) and undertake some initial evaluations on selected water utilities in South Africa. This first project did not allow for analysis and checking of the data and results that came from the water suppliers due to budget and time constraints and there were many anomalies which were identified but never corrected. As the software has now been available for sometime in South Africa, it was considered worthwhile to build on the previous work and to carry out a detailed analysis of leakage in selected water utilities. The project was then initiated to compare the levels of leakage of 30 water utilities in South Africa. The results will become part of a larger International Water Association (IWA) initiative to gather leakage information from around the world by creating an international data set which will allow comparisons to be made of leakage levels between various countries. A number of water utilities in South Africa were requested to provide data on their respective systems including length of mains, number of service connections, average operating pressure, systems input volume and the components of authorised consumption. The data were processed through

This paper was originally presented at the 2004 Water Institute of South Africa (WISA) Biennial Conference, Cape Town, South Africa, 2-6 May 2004.

* To whom all correspondence should be addressed.

II:+2712 346-3496; fax: +2712 346-9956;

e-mail: caryns@wrp.co.za or ronniem@wrp.co.za the BENCHLEAK model and the results carefully screened for errors.

While the main aim of the project was to gather a data set of water suppliers in South Africa and to determine the levels of leakage being experienced, it was also necessary to investigate certain issues in depth to ensure that a standard format was being used. Some confusion had been experienced by the water utilities in the previous project with regard to certain of the input parameters for the model, namely, the number of service connections and the estimation of apparent losses. It is of little value comparing water utilities if they have made their own assumptions with regard to key elements of the benchmarking calculation.

For this reason, standard drawings were developed to assist users in assessing the number of service connections in their systems as well as the levels of apparent losses. The apparent loss figure was previously very subjective and open to interpretation. In this project the apparent losses have been evaluated in a more detailed and pragmatic approach. The age of the meters and the number of illegal connections are the main factors influencing the apparent losses in South Africa. The apparent losses for each individual water utility have been assessed according to these factors.

This paper presents the main findings of the project. Results from the various water utilities included in the data set are presented and discussed. Standard approaches for dealing with various inputs required for the model have been developed and are presented.

\section{The BENCHLEAK model}

The BENCHLEAK model was developed through the Water Research Commission in order to facilitate the evaluation of leakage levels and, in particular, non-revenue water, in potable water distribution systems (Mckenzie and Lambert, 2002). It is a simple, user-friendly model that is based on an excel spreadsheet and provides various performance indicators for non-revenue water and real losses. The model was used in the evaluation of 30 water utilities throughout South Africa, which were then compared to international water utilities. The input for the model was provided by the water utilities and a brief description of each follows. 


\section{BENCHLEAK input}

\section{Length of mains}

The length of mains is the total length of the bulk and distribution mains in a particular system. All pipes excluding the connection pipes are considered to be mains. This value can sometimes cause confusion in that water utilities are unsure as to what it includes. It is in fact the total length of transmission and distribution mains.

\section{Number of service connections}

This value has been a topic of debate amongst many water demand management specialists, and is discussed in more detail later in this paper. It is defined as the number of connections to the mains.

\section{Operating pressure}

The average operating pressure for the whole system over the period in question.

\section{Population}

The population that is served by the water utility in question. This parameter plays no real role in the model and is simply used to calculate the per capita consumption.

\section{System input volume}

The total volume input into the water supply system, allowing for known errors. It is broken up into water supplied by own sources as well as water supplied by other suppliers.

\section{Components of authorised consumption}

Also divided into various sections namely, billed metered, billed unmetered, unbilled metered and unbilled unmetered. Examples of each of these can be seen in Table 1 .

\begin{tabular}{|c|c|}
\hline \multicolumn{2}{|c|}{$\begin{array}{l}\text { TABLE } 1 \\
\text { Examples of the various components on authorised } \\
\text { consumption }\end{array}$} \\
\hline Billed metered & $\begin{array}{l}\text { Domestic consumersIndustrial/commercial } \\
\text { consumers }\end{array}$ \\
\hline Billed unmetered & Consumers charged on a flat rate tariff basis \\
\hline Unbilled metered & Schools \\
\hline & Recreational parks \\
\hline & Some government buildings \\
\hline & Police stations \\
\hline & Municipal swimming pools \\
\hline Unbilled unmetered & Fire fighting \\
\hline & Mains flushing \\
\hline
\end{tabular}

\section{Valuation of real and apparent losses}

For this section unit values are derived from the costs of water purchased and the average price of water sold by the water utility. An annual cost of running the system is also input required by the model.

\section{BENCHLEAK output}

The BENCHLEAK model carries out a number of calculations providing the user with useful output that can be used to compare various water utilities. The main comparison values are as follows:

\section{Unavoidable annual real losses (UARL)}

The minimum level of real losses for a specific system that can be achieved under the most efficient operating conditions. It is an indication of the level of leakage that can theoretically be achieved if everything possible is done to minimise the leakage and is generally not an achievable target for most water suppliers, since the UARL is well below the economic level of leakage.

\section{Apparent losses (AL)}

Unauthorsied consumption (theft or illegal use) as well as all technical and administrative inaccuracies associated with customer metering and billing. It is given as a percentage of the total water lost in the system ie. system input less the authorised consumption. A systematic estimate should be made from local knowledge of the system and an analysis of technical and administrative aspects of the customer metering system. Apparent losses are discussed in more detail later.

\section{Current annual real losses (CARL)}

The physical water losses from the pressurised system, up to the point of measurement of customer use. Calculated as the total water lost less the apparent losses. The annual volume lost through all types of leaks, bursts and overflows depends on frequencies, flow rates, and average duration of individual leaks.

\section{Infrastructure leakage index (ILI)}

The infrastructure leakage index is a non-dimensional index which provides an indication of how serious the leakage occurring in a particular area is compared to the theoretical minimum level of leakage that can be achieved. It is a ratio of the Current Annual Real Losses to Unavoidable Annual Real Losses (Lambert et. al, 1999).

\section{Results from 30 water suppliers}

The main objective of the project was to gather data from as many water suppliers throughout South Africa as possible, and to enter the data into the BENCHLEAK model. The output was then closely screened for errors, and a representative short list of 30 suppliers was developed. Missing data was the main reason for leaving out suppliers which had volunteered information. Table 2 provides data from the short listed suppliers. Each supplier has been allocated a number to which it will be referred.

The ILI values for the 30 suppliers range from 0.08 to 15.96 . No. 4's 0.08 is a result of the very similar system input value (19 $17910^{3} \mathrm{~m}^{3} /$ year) and authorised consumption value (19 089 $10^{3} \mathrm{~m}^{3} /$ year) and is very likely incorrect. The ILI value often highlights problems with the suppliers base data due to either meter error or simple fudging of information. Anything under 2.0 in South Africa should be reviewed critically as it is likely to be erroneous due to some form of data error. Utilities 12 and 21 require closer examination and no. 4 will be left out of the final data set. No. 8 has a very high ILI value due to the high difference in input (34 $73910^{3} \mathrm{~m}^{3} /$ year) and consumption (17 $32310^{3} \mathrm{~m}^{3} /$ year). The average ILI value for all 30 utilities is 5.69. This can be compared to ILI values calculated by International Water Data comparisons LTD for 27 supply systems in 19 countries that range from 1.0 to 10.0 with an average value of 4.2 .

The norm for UARL is approximately 50 litres per connection per day at standard pressure. Most of the suppliers fall within this range except for $30,22,7,19$ and 11 , which are all greater than 80 litres per connection per day. The average UARL for the utilities is 59.93 litres per connection per day. 
TABLE 2

A summary of the data and results of the 30 South African water utilities

\begin{tabular}{|c|c|c|c|c|c|c|c|c|c|c|c|c|}
\hline No. & $\begin{array}{l}\text { Mains } \\
\text { length }\end{array}$ & $\begin{array}{l}\text { Service } \\
\text { cons. }\end{array}$ & Density & Pressure & Population & $\begin{array}{c}\text { Population/ } \\
\text { serv. con. }\end{array}$ & UARL & $\begin{array}{c}\text { System } \\
\text { input }\end{array}$ & $\begin{array}{l}\text { Authorised } \\
\text { consumption }\end{array}$ & AL & ARL & ILI \\
\hline & km & no. & no. / km & m & no. & & $\ell /$ con'd & $10^{3} \mathrm{~m}^{3} / \mathrm{yr}$ & $10^{3} \mathrm{~m}^{3} / \mathrm{yr}$ & $10^{3} \mathrm{~m}^{3} / \mathrm{yr}$ & $10^{3} \mathrm{~m}^{3} / \mathrm{yr}$ & \\
\hline 1 & 718 & 31200 & 43 & 50 & 218010 & 7.0 & 61 & 22039 & 17134 & 981 & 3924 & 5.68 \\
\hline 2 & 1069 & 60208 & 56 & 40 & 663037 & 11.0 & 45 & 24344 & 9583 & 2952 & 11809 & 12.12 \\
\hline 3 & 1315 & 79306 & 60 & 50 & 305600 & 3.9 & 55 & 30284 & 25362 & 984 & 3938 & 2.48 \\
\hline 4 & 762 & 52928 & 69 & 45 & 255000 & 4.8 & 48 & 19179 & 19089 & 18 & 72 & 0.08 \\
\hline 5 & 2400 & 198951 & 83 & 60 & 994755 & 5.0 & 61 & 83788 & 71948 & 2368 & 9472 & 2.14 \\
\hline 6 & 35 & 1156 & 33 & 51 & 4540 & 3.9 & 69 & 760 & 566 & 29 & 165 & 5.68 \\
\hline 7 & 38 & 1142 & 30 & 63 & 6170 & 5.4 & 88 & 1110 & 940 & 26 & 145 & 3.93 \\
\hline 8 & 678 & 44550 & 66 & 50 & 262943 & 5.9 & 54 & 34739 & 17323 & 3832 & 13584 & 15.56 \\
\hline 9 & 456 & 21100 & 46 & 50 & 108905 & 5.2 & 59 & 12043 & 8965 & 616 & 2462 & 5.38 \\
\hline 10 & 27 & 557 & 21 & 35 & 2109 & 3.8 & 59 & 250 & 203 & 7 & 40 & 3.36 \\
\hline 11 & 2082 & 75059 & 36 & 75 & - & - & 97 & 135687 & 98616 & 7354 & 29417 & 11.02 \\
\hline 12 & 28 & 1017 & 36 & 40 & - & - & 52 & 1419 & 1391 & 6 & 22 & 1.16 \\
\hline 13 & 103 & 5872 & 57 & 50 & - & - & 56 & 3654 & 3113 & 108 & 433 & 3.62 \\
\hline 14 & 1552 & 94105 & 61 & 50 & 899582 & 9.6 & 55 & 52389 & 40999 & 2278 & 9112 & 4.84 \\
\hline 15 & 1275 & 69000 & 54 & 50 & 601924 & 8.7 & 57 & 36353 & 27159 & 1839 & 7355 & 5.21 \\
\hline 16 & 431 & 22700 & 53 & 50 & 181966 & 8.0 & 57 & 11505 & 5997 & 1322 & 4186 & 8.85 \\
\hline 17 & 52 & 1478 & 28 & 35 & 5306 & 3.6 & 50 & 742 & 594 & 22 & 126 & 4.65 \\
\hline 18 & 746 & 29760 & 40 & 50 & 237378 & 8.0 & 63 & 21603 & 8730 & 2575 & 10298 & 15.15 \\
\hline 19 & 920 & 30786 & 33 & 70 & - & - & 94 & 18347 & 11814 & 1307 & 5226 & 4.97 \\
\hline 20 & 358 & 10200 & 28 & 40 & - & - & 57 & 26976 & 24207 & 554 & 2215 & 10.39 \\
\hline 21 & 467 & 21577 & 46 & 50 & 138000 & 6.4 & 71 & 7257 & 6058 & 240 & 959 & 1.71 \\
\hline 22 & 2390 & 112000 & 47 & 70 & - & - & 83 & 85020 & 66465 & 3711 & 14844 & 4.38 \\
\hline 23 & 386 & 18931 & 49 & 45 & 117000 & 6.2 & 53 & 12254 & 9992 & 339 & 1923 & 5.3 \\
\hline 24 & 2943 & 191518 & 65 & 45 & - & - & 48 & 139685 & 113369 & 5299 & 21197 & 6.26 \\
\hline 25 & 732 & 36253 & 50 & 35 & 350000 & 9.7 & 41 & 39153 & 37103 & 410 & 1640 & 3.04 \\
\hline 26 & 166 & 7817 & 47 & 40 & 20000 & 2.6 & 47 & 2966 & 2377 & 118 & 471 & 3.49 \\
\hline 27 & 1850 & 145000 & 78 & 45 & 833700 & 5.7 & 56 & 69775 & 56863 & 2582 & 10330 & 4.21 \\
\hline 28 & 263 & 12555 & 48 & 30 & 78000 & 6.2 & 35 & 12019 & 10083 & 252 & 1684 & 10.41 \\
\hline 29 & 353 & 11283 & 32 & 33 & 45000 & 4.0 & 45 & 4427 & 3477 & 190 & 760 & 4.19 \\
\hline 30 & 1571 & 97592 & 62 & 75 & - & - & 82 & 46218 & 36048 & 2034 & 8136 & 2.79 \\
\hline
\end{tabular}

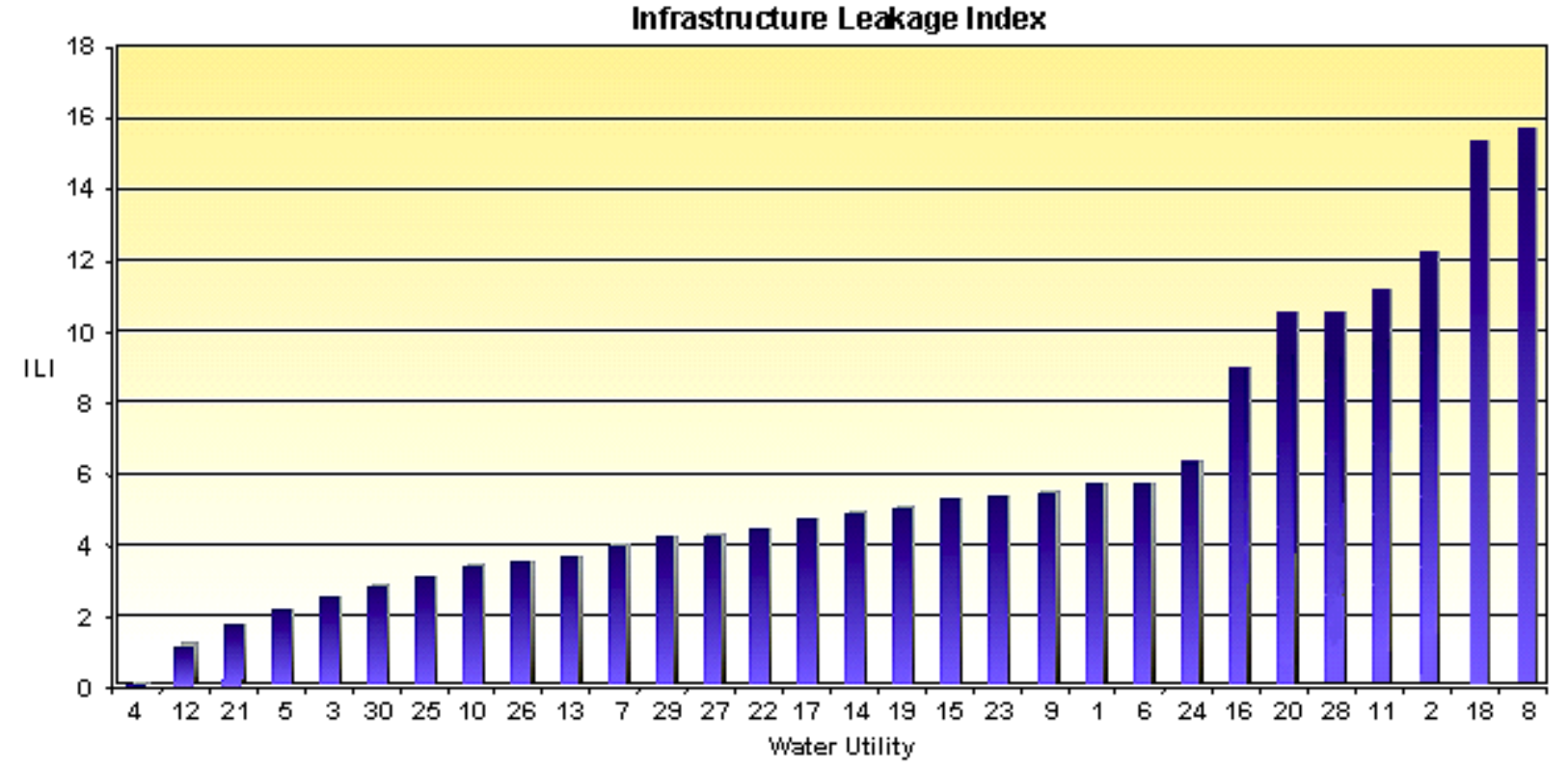

Figure 1

Chart showing results of the infrastructure leakage indices 


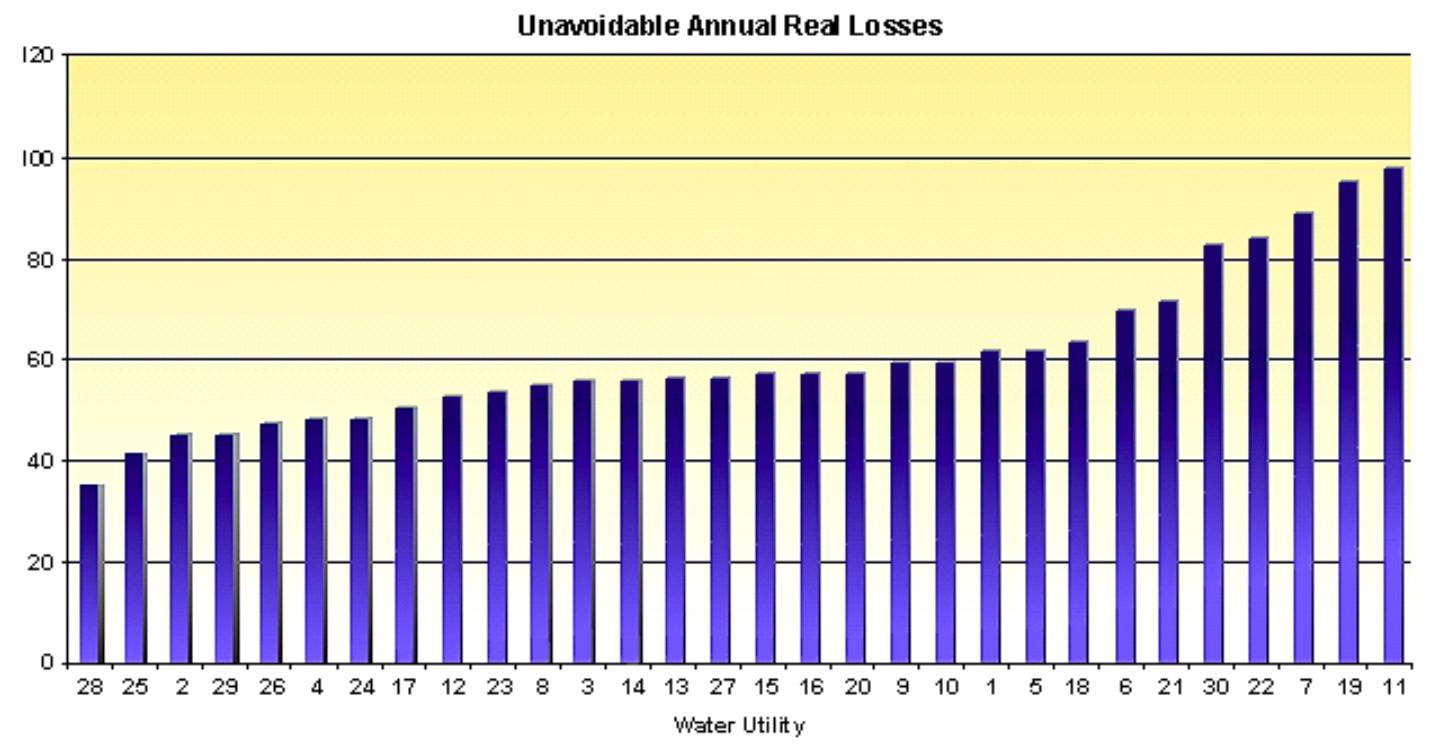

Figure 2

Chart showing

results of the

unavoidable

annual real losses

Apparent losses

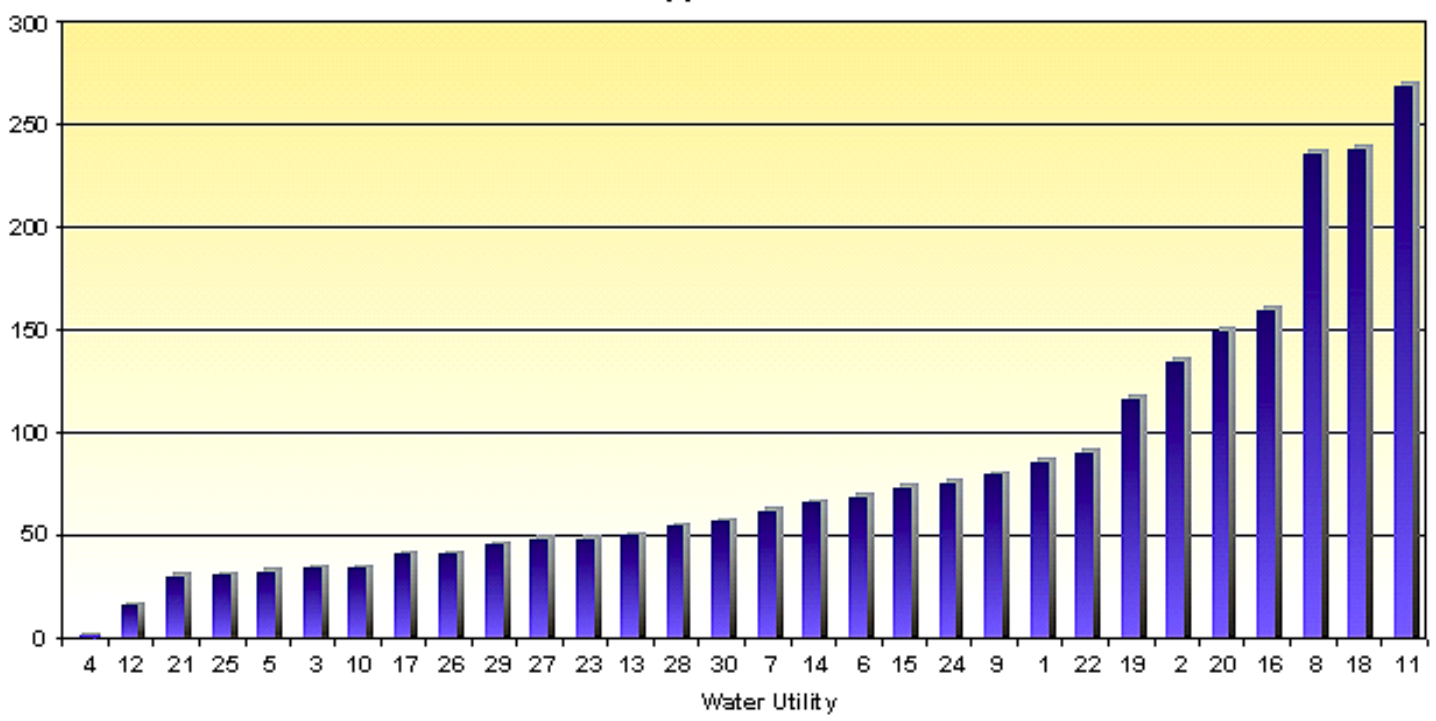

Figure 3

Chart showing

results of the

apparent losses

Figure 4

Chart showing

results of the

annual real

losses

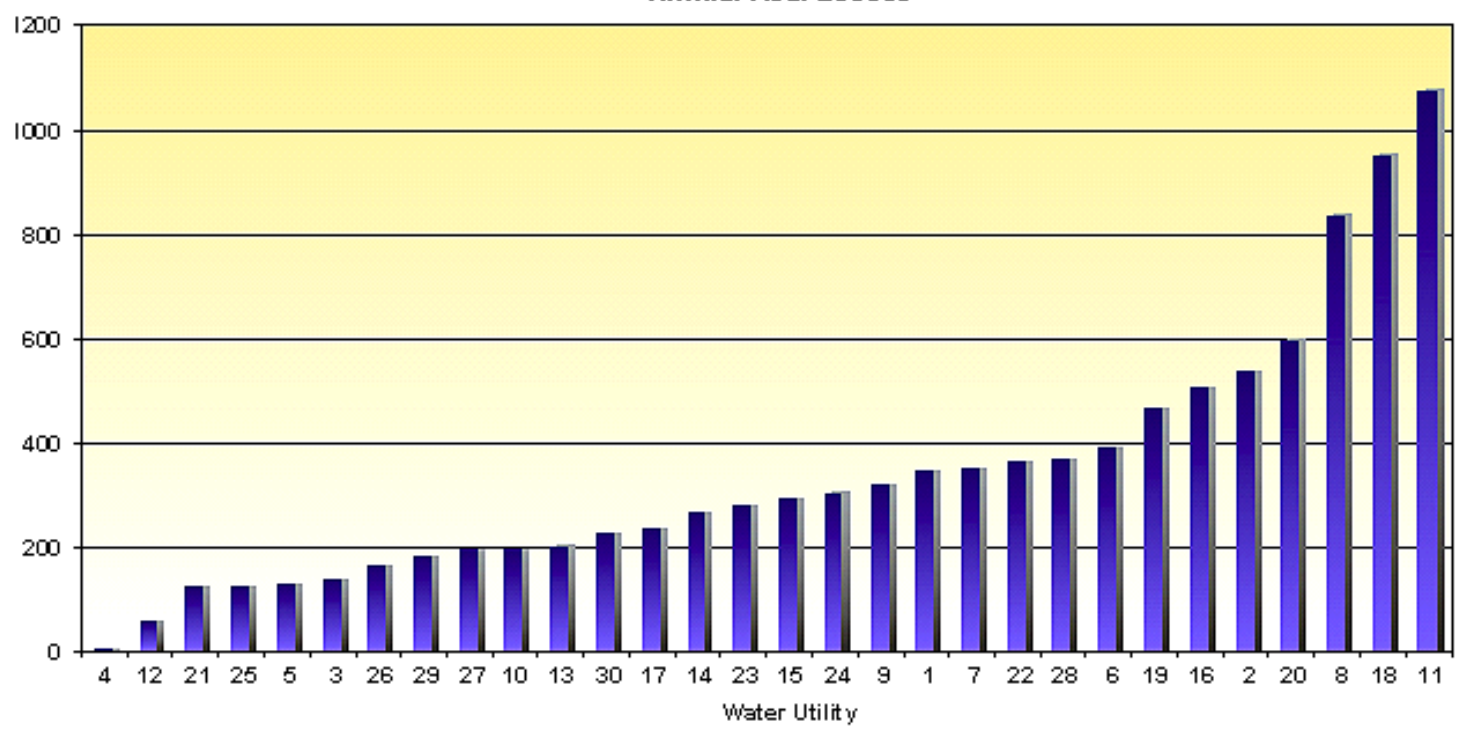


The apparent losses have been presented in units of litres per connection per day rather than $\mathrm{m}^{3} / \mathrm{year}$ in order to best compare them. The average is 82.83 litres per connection per day. Utility 11 has the highest apparent losses of 268 litres per connection per day.

The average annual real loss is 340 litres per connection per day. This compares to the International data set average of 276 litres per connection per day. An average of $15.7410^{3}$ litres per km mains per day was obtained for the 30 utilities. The international data set's average was $12.5510^{3}$ litres per km mains per day.

One can see from the four graphs presented here that various performance indicators can be used to compare water utilities. Utility 8 has the highest ILI value, but its ARL is not the highest. Utility 11 has the highest ARL value of 1073.7 litres per connection per day which is unacceptably high.

\section{Problem areas}

At the outset of the project, a few problem areas existed that caused confusion for the water suppliers providing information. An objective of the project was to highlight these "grey areas" and to propose standard solutions to be used in the future. The first issue is that of the number of service connections. It was unclear precisely what this number meant and which was the best way to represent the number of service connections. Another unclear area that required clarification was that of apparent losses. Previously, a value of $20 \%$ was suggested as a lump sum of the total losses and this was assumed to be apparent losses. However, this is not entirely correct due to the many factors that contribute to apparent losses. Apparent losses could be well above $20 \%$ in some areas, and might not necessarily be $20 \%$ in others. Lastly the length of underground pipe was looked at. This value is included in the calculation of UARL, and it was not clear exactly what length was required. These three problem areas are discussed in more detail in the following section.

\section{Number of service connections}

The IWA Manual of Best Practice 'Performance Indicators for Water Supply Services’ (Alegre et. al., 2000) clearly defines a service connection as "the authorised pipe connecting the main to the measurement point or the customer stop-valve, as applicable. Where several registered customers or individually occupied premises share a physical connection or tapping off the main, eg. apartment buildings, this will still be regarded as the one connection for the purposes of the applicable Performance Indicator, irrespective of the configuration and number of customers or premises". The "number of service connections" Ns variable is used to calculate the UARL in a system, by taking into consideration the unavoidable leakage expected to occur on service connections between the main and the stop-valve or property line. It is then added to the other components of UARL (on mains, and on pipes between the stop-valve / property line and the customer meter) to calculate the total UARL as follows:

$$
\mathrm{UARL}=[(18 \times \mathrm{Lm})+(0.8 \times \mathrm{Ns})+(25 \times \mathrm{Lp})] \times \mathrm{P}
$$

where:

$$
\begin{aligned}
\mathrm{UARL}= & \text { Unavoidable Annual Real Losses }(\ell / \mathrm{conn} \cdot \mathrm{d}) \\
\mathrm{Lm}= & \text { length of mains }(\mathrm{km}) \\
\mathrm{Ns}= & \text { number of service connections } \\
\mathrm{Lp}= & \text { length of unmetered underground pipe from street } \\
& \text { edge to customer meter }(\mathrm{km}) \\
\mathrm{P} & \text { average operating pressure at average zone } \\
& \text { point }(\mathrm{m})
\end{aligned}
$$

Experience shows that most water suppliers do not know how many saddle connections they have and what proportion support one, two, four or eight properties. However, they do usually have information on the numbers of billed accounts, customer meters, or stands (the South African term for defined plots of land). It is also usually possible to count the number of stop-valves sited outside the stands, typically in the pavement. By considering a representative sample of service connection layouts for a particular system, it is usually possible to produce a correlation between one of these parameters (billed accounts, customer meters or stop-valves) and the number of service connections Ns (physical connections to the mains) for that particular system.

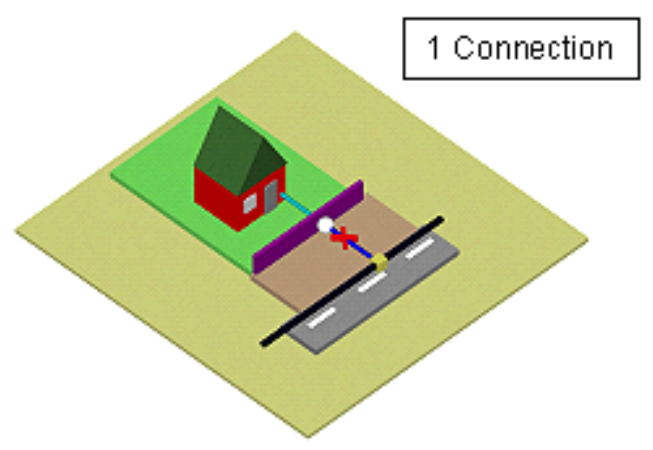

Figure 5

A single billed metered property on a street, situated on a single stand. There is one physical connection from the main that goes to the stop-valve, on to the external meter in the pavement and then on to the stand/property.

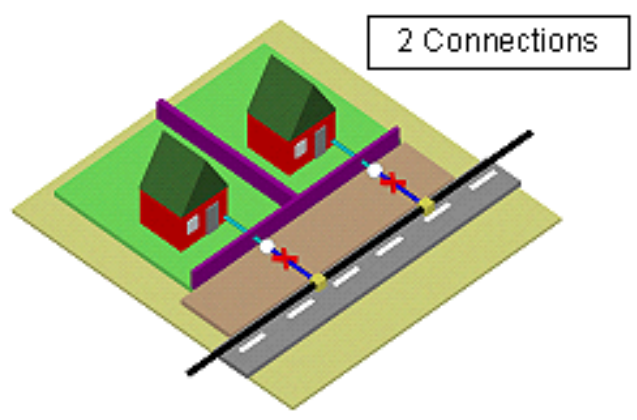

Figure 6

Two single billed metered properties on a street, each situated on their own separate stands. There are two physical connections onto the main, one for each property, and therefore also two stop-valves and two meters.

If all service connection layouts were as simple as Figures 5 and 6 that follow, there would be no uncertainty in calculating Ns from one of the other parameters, the ratio would be one to one. However, there is a wide variety of different layouts in South Africa and an even wider range internationally. In practice the situation in most reticulation systems is not clear-cut and defining the number of service connections can sometimes be confusing.

According to the current IWA definition of a service connection, Figure 6 would count as two service connections. In contrast, the layout for two separate properties in Figure 7 below would only count as one service connection, as there is only one physical connection to the main. However, the argument arises:- does the system layout in Figure 6 necessarily produce double the unavoid- 
able leakage than that of the Figure 7 layout? The number of "fittings" (here defined as points breaking the pipe's continuity, excluding the meter) where background leakage and detectable leaks are most likely to occur, is four for Figure 6 and also four for Figure 7 (Figure 6 being at the two physical connections to the main and the two stop-valves; Figure 7 being the one physical connection onto the main, the T-piece and the two stop-valves). Therefore, theoretically the unavoidable leakage resulting from Figure 7 should be approximately the same as the unavoidable leakage from Figure 6. For this reason it was proposed that the configuration shown in Figure 7 be considered as 2 connections. Similarly, Figure 8 would represent 4 connections, even though there is only one mains tapping.

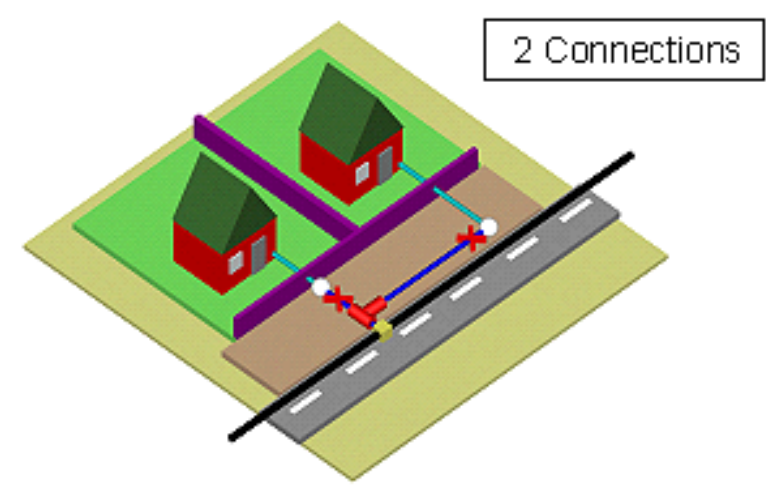

Figure 7

Two billed metered properties on a street, each situated on their own stand. There is only one physical connection onto the main, with a T-piece on the connection pipe to the second house. There are two meters.

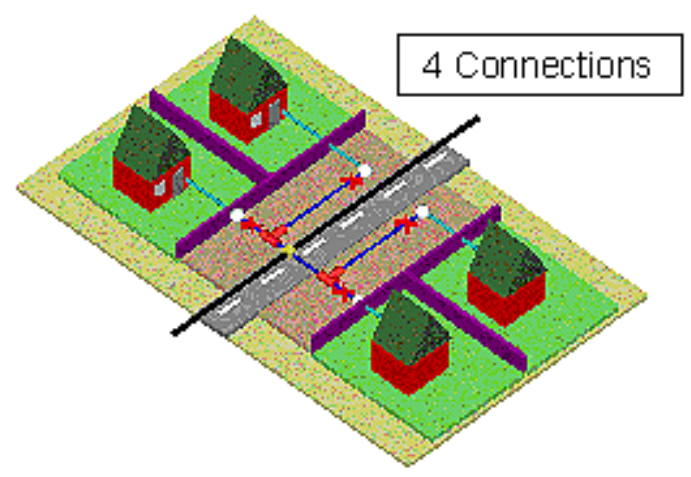

Figure 8

Two properties on one side and two on the other side of a street. There is only one physical connection onto the main, with two connection pipes, one to each side of the street. Each connection pipe then branches at a T-piece to two stop-valves, each with its own meter.

A trend become evident having looked at the diagrams closer and the proposal was therefore made to make Ns equal to the number of properties, or stop valves, which is in most cases the same as the number of customer meters. This is in contradiction to the IWA definition in that when more than one premises share a particular connection or tapping off the main, the proposal was to choose the number of connections equal to the number of premises rather than the number of connections. The main purpose for the change was to reduce the complexity of gathering data with a method of approaching the Ns value on a more practical basis.

This proposal was accepted by the IWA with a few notable exceptions. A valid point put forward was the topic of confidence limits. New leakage assessment models currently available (Aqualibre and Fastcalc) have the option to include 95\% confidence limits for all parameters, including the Ns. A moderate uncertainty in Ns will have comparatively little effect upon the 95\% confidence limits for the Performance Indicator.

A main concern when using the number of properties or meters was in situations where a block of flats is served by one tapping off the main. Some apartment blocks in parts of Europe contain only one service connection serving numerous customer meters each adjacent to its own stop-valve. As these meters tend to be read frequently, any leaks at the stop-valve or meter should be quickly detected as part of the meter reading process, and it would be overgenerous to use the number of stop-valves as a surrogate for Ns when calculating the UARL. It was this which lead to considering the merits of standardising on counting the number of stop-valves, but reducing the ' 0.80 ' coefficient for Ns in situations where the ratio of "number of stop-valves to number of physical connections to mains" is large (Lambert, 2004).

For the UARL calculation, the coefficient of $0.8 \mathrm{l} /$ service conn/ day/metre of pressure used in the equation was based on one service connection to one customer. Rather than changing the way Ns is calculated for different situations, it was decided that it would be more practical to change the coefficient applied to Ns for some situations. The equation was proposed, relating the coefficient (0.8) to the ratio of number of stop-valves to number of physical connections to the main (Nm).

$$
\text { Ns Coefficient }=0.8(1.0-\mathrm{A} \times \log (\mathrm{Ns} / \mathrm{Nm})
$$

The value of 'A' could be adjusted to give coefficients which tied in with theoretical calculations based on number of joints.

Perhaps one of the most significant sources of error or confusion occurs when the 'number of billed accounts' is used as a surrogate for Ns when calculating UARL. If the 'number of billed accounts' is the only data readily available, then it was suggested that the number of billed accounts be multiplied by an assessed factor (less than 1) which takes into account the numbers of billed accounts served by a single service connection, with $95 \%$ confidence limits.

For example, consider a utility with 500000 billed accounts, of which 400000 have their own separate service connection; the remaining 100000 billed accounts are in multi-residential blocks. If the average number of multi-residential accounts per multiresidential block is 10 , and each multi-residential block has one service connection, then the number of service connections is:

$400000+1 \times(100000 / 10)=410,000$ and the ratio of service connections to billed accounts is:

$410000 / 500000=0.82$ with 95\% confidence limits of (say) $\pm 5 \%$.

\section{Apparent losses}

Apparent losses, often referred to as non-physical or paper losses, are in many cases the most expensive water losses to occur from a system since they represent a direct loss of revenue to the water supplier. In cases where the water bills are based on the metered consumption, any losses occurring due to meter error or data handling and/or processing, will result in reduced sales revenue (Thornton and Rizzo, 2002). 
Meter error is often thought to be the main cause of apparent losses in a water system and can be due to wear and tear, incorrect meter installation, lack of maintenance, incorrect meter type or incorrect sizing. Data transfer errors can also contribute to the apparent losses. These can include merely recording an incorrect reading, incorrect interpretation of a decimal point or incorrect calibration of the meter. Estimated readings are often used to generate water accounts when a meter is situated in such a manner that it is difficult to read, and such assumed figures are often inaccurate.

Another contribution to apparent losses in South Africa and other developing countries is theft or illegal connections. Water may be stolen from a number of points in the system, but most commonly it is stolen from the customer supply point or fire hydrants. Customers have been known to tamper with water meters, by placing a magnet close to the register magnets to interfere with the correct rotation of the register and therefore causing lower readings. Hydrants are often abused by construction workers, street cleaners, taxi drivers who wash their vehicles and others who merely use the water for drinking or bathing. In addition to blatant theft, many accounts go unnoticed in the system. An example may be a temporary construction feed, which eventually becomes a permanent supply point but is never metered, billed or included on the billing database.

In the past a simple lump sum was used to express apparent losses in terms of the total losses and a default value of $20 \%$ was suggested but could be changed by the user. This is a very simple approach, however, and is not scientific. In South Africa for example, an area such as Sandton in Johannesburg is unlikely to experience the same level of water theft as say Soweto, and might in fact have a policy of replacing or servicing their meters every 5 years or so. To then assume that both Sandton and Soweto be given an estimate of $20 \%$ for apparent losses would be unrealistic. To overcome this problem a simple yet effective approach was adopted.

Water utilities were asked to classify their expected illegal connections as very high, high, average, low and very low. They were also asked to provide information on their water meters in terms of accuracy and age. Lastly they were asked to provide an estimate on the accuracy of their billing data in terms of good, average and poor. Table 3 presents a more pragmatic and realistic approach to the estimate of apparent losses for a typical system (ie. non flat rate tariff) based on the information received.

For example, in a non flat rate tariff area, if a water utility has a high occurrence of illegal connections ( $8 \%$ ), the meters in place are more than 10 years old but the water quality of the area is fairly good ( $8 \%$ ) and the data transfer side is average (5\%), the apparent loss estimate would be $21 \%$.

The information on the meters was estimated from the fact that Europe has a compulsory replacement programme on all meters every five years. Most of the domestic meters in place in South Africa are similar to the European meters. Many factors play a role in the accuracy of a meter, but were excluded in order to minimise complexity, with the exception of the water quality factor which has a major influence on the lifespan of a water meter.

The flat rate tariff ratio is to include areas, such as townships, where the flat rate charged is less than the amount actually being used, which can have a major impact on apparent losses. The following example can be used to illustrate the problem. If an area
TABLE 3

oss percentages for a typical system

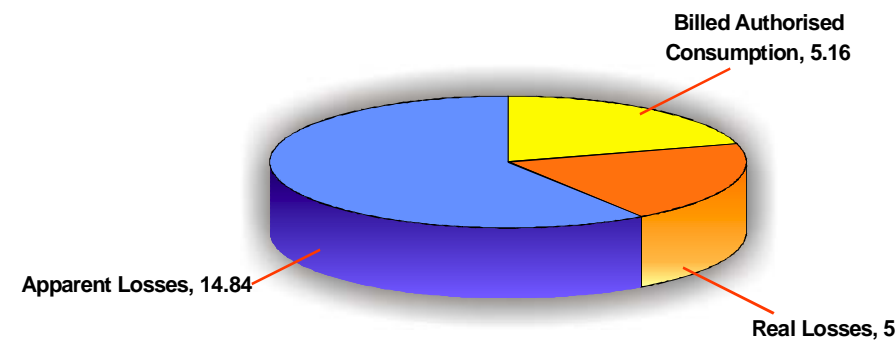

Figure 9

A breakdown of the water used in the example area

with 43000 connections is charged on a flat rate of $10 \mathrm{k} \ell /$ month. This value may not necessarily be recovered by the users, however, it is billed and is therefore considered to be part of the billed authorised component of the water balance. This amounts to 5.16 mill $\mathrm{m}^{3}$ / year. However, the water utility measures the water supplied to be $25 \mathrm{mill} \mathrm{m}^{3} /$ year. The sewerage return flow measured to be $18 \mathrm{mill} \mathrm{m}^{3}$ / year and garden irrigation is estimated to be 2 mill $\mathrm{m}^{3} /$ year. The quantity of water flowing through the 43000 properties is in fact $20 \mathrm{mill} \mathrm{m}^{3} /$ year (18 mill m $3 /$ year $+2 \mathrm{mill} \mathrm{m}^{3} /$ year), however, they are only billing $5.16 \mathrm{mill} \mathrm{m}^{3} /$ year. The apparent losses becomes $14.84 \mathrm{mill} \mathrm{m}^{3}$ year $\left(20 \mathrm{mill} \mathrm{m}^{3}\right.$ / year $-5.16 \mathrm{mill} \mathrm{m}^{3} /$ year) and the real losses are then 5 mill m³/year ( $25 \mathrm{mill} \mathrm{m}^{3} /$ year $5.16 \mathrm{mill} \mathrm{m}^{3} /$ year $-14.84 \mathrm{mill} \mathrm{m}^{3} /$ year). Figure 9 shows a pie cart of the example area.

It should be noted, however, that it is unlikely that the apparent losses can all be converted to revenue water by proper metering and billing since when payment is enforced, the level of consumption is likely to reduce dramatically. This is contrary to the normal assumption that reduction of apparent losses will result in greater revenue water. The normal practice of multiplying the apparent losses by the selling price of water is not appropriate in some cases and a more realistic value of the losses can be estimated using the purchase price (or product price) of water.

\section{Length of underground pipe}

The last issue that requires clarity is the length of underground pipe which is the third term in the UARL calculation. There was some confusion over what should be included and what is already taken into account in the Ns component of the calculation. If the meters are located at a street edge then it is assumed a particular length of 
pipe has already been included in the connection component of the UARL. In such cases, no additional allowance is made for the length of underground pipe. It is only included when it is located beyond the property boundary in which case the average length of underground pipe is used.

The section after the street/property line can be ignored in the South African context, as most meters are located close to the street / property line, and this length has already been included in the Ns part of the UARL calculation.

\section{Summary}

The BENCHLEAK software is a powerful tool for assessing and comparing leakage amongst water utilities, both local and international. From the results of the 30 South African water utilities to be included in the international data set, it appears that South Africa is in accordance with world norms in terms of their performance indicators. There is room for improvement for some water utilities and suggestions have been made on how to achieve better levels of leakage.

In summary, the solution proposed to solve the number of service connections debate is to base the calculation of Ns on the number of stop-valves and to include hydrants with separate mains connections. For systems where the ratio of stop-valves to physical connections is high, reduce the coefficient for Ns in the UARL equation in accordance with a published table.

The apparent losses have been looked at in more detail in this project and a more pragmatic approach is proposed. This is to break the apparent loss components down into various factors that contribute, and to assess each water utility differently according to these factors rather than merely using a lump sum estimate of apparent losses.

\section{References}

ALEGRE H, HIRNER W, MELO BAPTISTA J and PERENA R (2000) Performance indicators for water supply services. IWA Operations \& Maintenance Committee.

LAMBERT A, BROWN TG, TAKIZAWA M and WEIMER D (1999) A review of performance indicators for real losses from water supply systems. AQUA (Dec 1999). ISSN 0003-7214.

LAMBERT A (2004) Personal contact.

McKENZIE RS and LAMBERT A (2002) Benchleak User Guide. Water Research Commission Report, TT 159/01.

THORNTON J and RIZZO A (2002) Apparent losses, how low can you go? Leakage Management Conference Proceedings, Lemesos, Cyprus, Nov 2002. 